\title{
Association between smoking and recurrence of venous thromboembolism and bleeding in elderly patients with past acute venous thromboembolism
}

\author{
Authors: \\ Philippe Carruzzo, MD; Marie Méan, MD²,4; Andreas Limacher, PhD, MAS, \\ $\mathrm{MSc}^{3}$; Drahomir Aujesky, MD, MSc ${ }^{2}$; Jacques Cornuz, MD, MPH${ }^{1}$; Carole Clair, \\ $\mathrm{MD}, \mathrm{MSc}^{1}$
}

Author Affiliations:

${ }^{1}$ Department of Ambulatory Care and Community Medicine, University of Lausanne, Lausanne (Drs. Carruzzo, Clair, and Cornuz); ${ }^{2}$ Department of General Internal Medicine, Bern University Hospital, Bern (Drs Méan, and Aujesky); ${ }^{3}$ Clinical Trials Unit Bern, Department of Clinical Research, and Institute of Social and Preventive Medicine, University of Bern, Bern (Dr. Limacher); ${ }^{4}$ Department of Internal Medicine, University hospital, Lausanne (Dr Méan)

Corresponding author:

Philippe Carruzzo, MD

Policlinique Médicale Universitaire

Rue du Bugnon 44

1005 Lausanne

Switzerland

Email: philippe.carruzzo@unil.ch

Phone: 0041768224192

Fax : 00413146106

Number of references: 28

Number of tables: $3(\max 8)$

Word count of the abstract: 249

Word count of the text: $2624(\max 4000)$ 


\begin{abstract}
Background: While the association between smoking and arterial cardiovascular events has been well established, the association between smoking and venous thromboembolism (VTE) remains controversial.
\end{abstract}

Objectives: To assess the association between smoking and the risk of recurrent VTE and bleeding in patients who have experienced acute VTE.

Patients/Methods: This study is part of a prospective Swiss multicenter cohort that included patients aged $\geq 65$ years with acute VTE. Three groups were defined according to smoking status: never, former and current smokers. The primary outcome was the time to a first symptomatic, objectively confirmed VTE recurrence. Secondary outcomes were the time to a first major and clinically relevant non-major bleeding. Associations between smoking status and outcomes were analysed using proportional hazard models for the subdistribution of a competing risk of death.

Results: Among 988 analysed patients, 509 (52\%) had never smoked, 403 (41\%) were former smokers, and $76(8 \%)$ current smokers. After a median follow-up of 29.6 months, we observed a VTE recurrence rate of 4.9 (95\% confidence interval [CI] 3.7-6.4) per 100 patient-years for never smokers, $6.6(95 \% \mathrm{Cl} 5.1-8.6)$ for former smokers, and $5.2(95 \% \mathrm{Cl}$ 2.6-10.5) for current smokers. Compared to never smokers, we found no association between current smoking and VTE recurrence (adjusted sub-hazard ratio [SHR] 1.05, $95 \% \mathrm{Cl} 0.49-2.28$ ), major bleeding (adjusted SHR $0.59,95 \% \mathrm{Cl} 0.25-1.39$ ), and clinically relevant non-major bleeding (adjusted SHR 1.21, 95\% Cl 0.73-2.02).

Conclusions: In this multicentre prospective cohort study, we found no association between smoking status and VTE recurrence or bleeding in elderly patients with VTE.

Key words: venous thromboembolism, recurrence, hemorrhage, smoking, aged 


\section{Introduction}

Venous thromboembolism (VTE), defined as deep vein thrombosis (DVT) and/or pulmonary embolism (PE), is a common disease[1]. The incidence of VTE increases with age, rising from $<1$ case per 1,000 person-years in persons aged $<50$ years to more than 6 cases per 1,000 person-years in persons aged $>80$ years [2-6]. Overall, $60 \%$ of VTE events occur in persons aged $\geq 65$ years $[1,2,7]$.

Several factors induced by smoking could promote the formation of a clot and the subsequent VTE. These mechanisms were often studied in researches on atherosclerosis, and smoking shares common biological consequences on the venous system. Smoking causes endothelial damage that can lead to a reduced capacity for dilatation (by a decreased activity of nitrous oxide) and increased vessel contraction (by stimulation of the release of catecholamines) [8-11]. This endothelial damage can lead to prothrombotic and pro-inflammatory states with an increased production of cytokines including IL-6, IL1B and TNF $[$ [8-11]. Those cytokines play major regulatory roles in the hepatic synthesis of acute phase proteins, including fibrinogen. As IL- 6 appears to be the principal procoagulant cytokine in humans, it could be an important link to VTE $[11,12]$. Moreover, there is a clear dose-effect relationship between number of cigarettes smoked per day and raised plasma fibrinogen concentration and conversely a reduction of it with smoking cessation [13].

The association between smoking and VTE remains controversial. While a metaanalysis reported no statistically significant relationship between smoking and first VTE (odds ratio $[\mathrm{OR}] 1.18,95 \%$ confidence interval [CI] 0.95-1.46) [14], a recent meta-analysis demonstrated that cigarette smoking was associated with a slightly increased risk for first VTE (pooled relative risk $1.23,95 \% \mathrm{Cl} 1.14-1.33$ ) in current smokers compared with never smokers [15]. 
Smoking interacts directly with the metabolism of vitamin $\mathrm{K}$ antagonists by increasing the required dosage to achieve and maintain a therapeutic international normalized ratio [16], potentially increasing the risk of VTE recurrence. Pathophysiologically, smoking may increase the clearance of warfarin and in this way reduce its anticoagulant effect. Therefore, smoking cessation or a decrease in smoking may lead to overanticoagulation and an increased risk of bleeding.

Evidence suggests that elderly patients who have experienced an acute VTE may have a higher risk of VTE recurrence, bleeding, and death than younger patients $[2,7]$. Given that the elderly are a rapidly growing population segment in Western societies and almost half of the elderly population is or has been exposed to smoking [17], it is of interest to examine the possible association between smoking and VTE recurrence and bleeding in this population. In a prospective multicenter cohort study, we aimed to assess the association between smoking status and the risk of recurrent VTE and bleeding in elderly patients with acute VTE. 


\section{Methods}

\section{Cohort sample}

The study was conducted between September 2, 2009 and December 62013 as part of Swiss Cohort of Elderly Patients with Venous Thromboembolism (SWITCO65+), a prospective, multicenter cohort study that assessed long-term medical outcomes in elderly patients with acute VTE from all five university and four high-volume nonuniversity hospitals in Switzerland. Consecutive patients aged $\geq 65$ years with acute, objectively confirmed symptomatic VTE were prospectively identified in the inpatient and outpatient services of all participating study sites. Exclusion criteria were catheter-related thrombosis, insufficient German or French-speaking ability, no follow-up possible (i.e., terminal illness), an inability to provide informed consent (i.e., severe dementia), or previous enrollment in the cohort. The detailed methodology of the SWITCO65+ cohort has been described elsewhere [2]. The study has been approved by the Institutional Review Board at each participating center. For the present study, we excluded patients with missing information about their smoking status.

\section{Baseline data collection}

For all enrolled patients, trained study nurses prospectively collected information about baseline demographics (age, gender, insurance status, living status, and educational level), comorbid conditions (active cancer, hepatic, cardiac, lung, renal, and cerebrovascular disease, and history of major bleeding), traditional cardiovascular risk factors (arterial hypertension, diabetes mellitus, hypercholesterolemia, body mass index, physical activity level), risk factors for VTE (active cancer, recent immobilization, major surgery, estrogen therapy), type and localization of the index VTE, VTE-related 
treatments (oral and parenteral anticoagulants), and concomitant antiplatelet/nonsteroidal anti-inflammatory drug therapy using standardized data collection forms.

Smoking habits, including self-reported smoking status, the average number of cigarettes smoked per day and years of smoking were assessed. We defined three possible smoking statuses: current smokers (i.e. patients reporting smoking $\geq 1$ cigarette per day at the time of the interview), former smokers (defined as smokers who had quit for $>6$ months) and never smokers. Current and former smokers were classified into three subgroups according to the number of pack-years smoked (defined as the number of packs of cigarettes smoked per day multiplied by the duration of smoking in years ): $\leq 20$, 21-40, and $>40$ pack-years.

\section{Study outcomes}

The primary outcome was the time to the recurrence of symptomatic, objectively confirmed VTE during follow-up, defined as new or recurrent PE or DVT based on previously published criteria $[18,19]$. We defined recurrent symptomatic VTE as acute chest pain, new or worsening dyspnea or cough, acute hemoptysis, or syncope coupled with an objective diagnosis of pulmonary embolism based on spiral computed tomography, pulmonary angiography, or autopsy, or a new unilateral leg pain or swelling coupled with an objective diagnosis of deep vein thrombosis based on ultrasonography or contrast venography.

The secondary outcome was the time to a first bleeding event. We defined major bleeding as fatal bleeding, symptomatic bleeding in a critical organ (intracranial, intraspinal, intraocular, retroperitoneal, intra-articular, pericardial, or intramuscular with compartment syndrome), bleeding with a reduction of hemoglobin $\geq 20 \mathrm{~g} / \mathrm{l}$, or bleeding leading to the transfusion of 2 units of packed red blood cells or more $[2,20]$. Non-major 
bleeding was defined as bleeding leading to a medical consultation or a visit to an emergency center, without fulfilling the criteria for a major bleeding [2].

Follow-up included one telephone interview and two surveillance, face-to-face evaluations during the first year of study participation and then semi-annual contacts, alternating between face-to-face evaluations (clinic visits or home visits in house-bound patients) and telephone calls as well as periodic reviews of the patient's hospital chart. During each visit/contact, study nurses interviewed patients to obtain information about the date and type of clinical events (recurrent VTE, bleeding, and death). If a clinical event had occurred, this information was complemented by reviewing medical charts and interviewing patients' primary care physicians and family members. We assessed outcomes using patient or proxy interviews, interview of the patient's primary care physician, and/or hospital chart review. A committee of three blinded clinical experts adjudicated all outcomes and classified the cause of all deaths as definitely due to PE, possibly due to $\mathrm{PE}$, due to major bleeding, or due to another cause. Final classification was made on the basis of the full consensus of this committee.

\section{Statistical analysis}

We compared baseline and outcome characteristics of never, current, and former smokers using chi-squared test for categorical variables and non-parametric KruskalWallis test for continuous variables. Smoking characteristics of current and former smokers were compared using chi-squared and Wilcoxon rank-sum test as appropriate. We calculated the incidence rate of a first VTE recurrence in each group and compared incidences among groups using the incidence rate ratio. We estimated the cumulative incidence of a first VTE recurrence by the Kaplan-Meier method and compared survivor functions across groups of patients with different smoking status and the quantity of pack-years smoked by the logrank test. 
We compared the percentage of time spent within one of three specified INR ranges $(<2.0,2.0-3.0,>3.0)$ across different smoking levels by analysis of variance (ANOVA), excluding the first seven treatment days and patients with no or only one INR measurement.

Associations between smoking status and the time to the first VTE recurrence were assessed by competing risk regression accounting for death as a competing event, according to the method of Fine and Gray (1999) [21]. The method yields sub-hazard ratios (SHR) with corresponding 95\% confidence intervals (Cls). Adjustments were done for age and gender and for variables associated with VTE recurrence, including prior VTE, active cancer, overt PE, and provoked VTE (defined as the presence of immobilization, major surgery, or current estrogen therapy during the last three months). For bleeding, adjustments were done for age and gender and for variables known to be associated with a higher bleeding risk, including chronic renal disease or or a creatinine clearance $<30 \mathrm{ml} / \mathrm{min}$., history of major bleeding, anemia, and concomitant antiplatelet treatment [22-25]. We adjusted all analyses for periods of anticoagulation treatment as a timevarying covariate. All analyses were done using Stata 13 (Stata Corporation, College Station, Texas).

\section{Results}

Of the 1003 patients enrolled in the cohort, 15 were excluded who did not allow use of their data $(n=8)$, withdrew early $(n=4)$, or missed information about smoking status $(n=3)$. Therefore, the final study sample comprised 988 patients of whom $509(52 \%)$ had never smoked, 403 (41\%) were former smokers and 76 (8\%) current smokers. The median follow-up duration was 29.6 months (IQR 18.8-36.2).

Patient baseline characteristics are described in table 1. Former and current smokers reported a median of 16 and 30 pack-years, respectively. Never smokers were 
more likely to be women and older than current and former smokers. Not surprisingly, current and former smokers were more likely to have lung disease and coronary heart disease and to receive concomitant antiplatelet therapy than never smokers. Finally, never smokers were more likely to receive vitamin $\mathrm{K}$ antagonists.

Overall, 204 patients (20\%) died during follow-up and 120 (12\%) had recurrent VTE (table 2). VTE recurrence did not vary by smoking status. Furthermore, 131 patients (13\%) had major and 199 (20\%) non-major bleeding events during the follow-up. Again, bleeding did not differ by smoking status.

Table 2 shows the incidence rate and incidence rate ratio (IRR) of VTE recurrence and major and non-major bleeding events for the three categories of smokers. Generally, compared with never smokers, current smokers tended to have a somewhat higher incidence rate of VTE recurrence (IRR $1.195 \% \mathrm{Cl}$ 0.4-2.8) and non-major bleeding events (IRR $1.295 \% \mathrm{Cl} 0.7-2.0$ ) but a lower incidence of major bleeding events (IRR $0.795 \% \mathrm{Cl}$ $0.2-1.5)$.

After adjustment, current smokers did not have a statistically significantly increased risk of VTE recurrence compared with never smokers (adjusted SHR $1.0595 \% \mathrm{Cl}$ 0.49-2.28). Similarly, there was no statistically significant association between active smoking and major (adjusted SHR 0.59 95\% Cl 0.25-1.39) and non-major bleeding events (adjusted SHR $1.2195 \% \mathrm{Cl}$ 0.73-2.02). We did not observe a statistically significant association between former smoking status and VTE recurrence or bleeding events. Moreover, we found no dose-response relationship between the number of pack-years and VTE recurrence in current and former smokers (data not shown). In patients who received treatment with vitamin $K$ antagonists, the percentage of time spent in the therapeutic range did not vary by smoking status (data not shown). 


\section{Discussion}

In this prospective cohort of elderly patients with VTE, the incidence of recurrent VTE and bleeding did not vary by smoking status. We found no dose-response relationship between the number of pack-years smoked and VTE recurrence. After adjustment, smoking status was neither associated with recurrent VTE nor with bleeding.

In the present study, the prevalence of active smoking (8\%) was similar to that observed in the general Swiss population aged 65 years or older [26] but former smokers were over represented in this cohort ( $41 \%$ vs $33.3 \%$ for $65-74$ years old and $26.7 \%$ for $\geq 75$ years old in the general Swiss population).

While the relationship between smoking and the first VTE has been well studied, very few studies have examined the relationship between smoking status and recurrent VTE. A cross-sectional study on the impact of cardiovascular risk factor on the risk of recurrent VTE reported no statistically significant association between cigarette smoking and recurrence of VTE (hazard ratio [HR] 1.20, 95\% Cl 0.88-1.52) [27]. In this study of younger patients (mean age 43.5 years), the authors did not differentiate current smokers from former smokers and compared ever smokers (current and former smokers) to never smokers. The reason why smoking seems to be associated with a first VTE but not with recurrent VTE remains unclear. However, after a first VTE event, smokers might reduce their cigarette consumption or make quit attempts, thus decreasing the risk of recurrent VTE. This might partly explain why smoking was not associated with an increased risk of VTE recurrence in the present study.

Regarding the possible dose-response relationship between smoking and VTE recurrence, we found no association between number of pack-years and VTE recurrence. A large 
population-based case-control study showed a clear dose-dependent, reversible association of smoking and the risk of a first VTE [28]. The limited number of smokers in our study ( $n=76$ ) might explain the absence of significant dose-response relationship.

In this cohort, smoking was not associated with an increased risk of major and clinically relevant non-major bleeding. Evidence suggests that smokers may need higher doses of warfarin per week than nonsmokers [16]. Smoking not only increases the dosage of required oral anticoagulant, but the variation of smoking amount or frequency may have an influence on the stability of anticoagulation making it difficult to maintain the anticoagulation in the therapeutic range. However, to our knowledge, there are no studies exploring the effect of smoking on the quality of oral anticoagulation. In our study, we found no difference in the percentage of time in the therapeutic range between smokers, former smokers, and never smokers. This may be due again to the limited sample of smokers. This study contains no information on quitting smoking, variation of consumption of cigarettes during the week or increased or decreased mean consumption of cigarettes.

The main strength of the study is that it prospectively followed patients over 3 years. It is the first prospective study examining the association between smoking status and outcomes in patients with VTE.

Our study has potential limitations. First, the study sample may not reflect the full prognostic spectrum of patients with VTE because analyzed patients were younger and more likely to be men than excluded patients. Thus we cannot rule out the possibility that the association between smoking status and bleeding and VTE recurrence would have been different in more severely ill patients. Second, an important limitation of this study is the small number of current smokers and the consequent lack of statistical power of our analysis. Moreover, the smoking status and number of cigarettes smoked a day were 
self-reported by patients and might be underestimated. Finally, smoking status was only assessed at baseline and was not updated over follow-up (no information on initiation, cessation or relapse of smoking). However, we can assume that initiation of smoking in a population age $>65$ years old is very unusual. Finally, our results are valid only for a Caucasian European population, given the relatively high socio-economical status of the population included and are not generalizable to other populations.

In conclusion, we found no differences in anticoagulation quality in smokers, former smokers, and never smokers in this prospective cohort of elderly patients with VTE. Moreover, smoking status was not significantly associated with VTE recurrence or bleeding. This study investigated for the first time the impact of smoking in this population. 
Addendum: P. Carruzzo, C. Clair, M. Méan and A. Limacher were responsible for the planning of the study, statistical analyses and drafting of the manuscript. J. Cornuz was responsible for intellectual review of the manuscript. D. Aujesky was the principal investigator and was responsible for the planning of the study, data collection, drafting of the manuscript, and obtaining funding from the Swiss National Science Foundation.

Acknowledgment: This study was supported by Swiss National Science Foundation grant no. 33CSCO-122659/139470. We thank all the investigators and the study personnel who made the SWITCO65+ study possible (in particular, Marc Righini, Kurt Jaeger, Hans-Jürg Beer, Beat Frauchiger, Joseph Osterwalder, Nils Kucher, Bernhard Lämmle, Jacques Cornuz, Anne Angelillo-Scherrer, Nicolas Rodondi, Sven Trelle, Christian M. Matter, Marc Husmann, Martin Banyai, Markus Aschwanden, Michael Egloff, Lucia Mazzolai, Olivier Hugli, and Henri Bounameaux).

Conflict of interest: The authors declare that they do not have any conflict of interest. 


\section{References}

1. Rosendaal FR, A VANHV, Doggen CJ. Venous thrombosis in the elderly. Journal of thrombosis and haemostasis : JTH. 2007;5 Suppl 1:310-7.

2. Mean M, Righini M, Jaeger K, Beer HJ, Frauchiger B, Osterwalder J, Kucher N, Lammle B, Cornuz J, Angelillo-Scherrer A, Rodondi N, Limacher A, Trelle S, Matter CM, Husmann M, Banyai M, Aschwanden M, Egloff M, Mazzolai L, Hugli O, et al. The Swiss cohort of elderly patients with venous thromboembolism (SWITCO65+): rationale and methodology. J Thromb Thrombolysis. 2013;36:475-83.

3. Oger E. Incidence of venous thromboembolism: a community-based study in Western France. EPI-GETBP Study Group. Groupe d'Etude de la Thrombose de Bretagne Occidentale. Thromb Haemost. 2000;83:657-60.

4. Cushman M, Tsai AW, White RH, Heckbert SR, Rosamond WD, Enright P, Folsom AR. Deep vein thrombosis and pulmonary embolism in two cohorts: the longitudinal investigation of thromboembolism etiology. Am J Med. 2004;117:19-25.

5. Naess IA, Christiansen SC, Romundstad P, Cannegieter SC, Rosendaal FR, Hammerstrom J. Incidence and mortality of venous thrombosis: a population-based study. Journal of thrombosis and haemostasis : JTH. 2007;5:692-9.

6. Kniffin WD, Jr., Baron JA, Barrett J, Birkmeyer JD, Anderson FA, Jr. The epidemiology of diagnosed pulmonary embolism and deep venous thrombosis in the elderly. Arch Intern Med. 1994;154:861-6.

7. Spencer FA, Gore JM, Lessard D, Emery C, Pacifico L, Reed G, Gurwitz JH, Goldberg RJ. Venous thromboembolism in the elderly. A community-based perspective. Thromb Haemost. 2008;100:780-8.

8. Franchini M, Mannucci PM. Association between venous and arterial thrombosis: clinical implications. European journal of internal medicine. 2012;23:333-7.

9. Landini L, Leone A. Smoking and hypertension: effects on clinical, biochemical and pathological variables due to isolated or combined action on cardiovascular system. Curr Pharm Des. 2011;17:2987-3001.

10. Funabashi N, Asano M, Komuro I. Predictors of non-calcified plaques in the coronary arteries of 242 subjects using multislice computed tomography and logistic regression models. Int J Cardiol. 2007;117:191-7.

11. Umesh Y, Mahemuti A, Zhou XH. Smoking is a risk factor for venous thromboembolism. Chin Med J (Engl). 2013;126:3177-80.

12. Arnson Y, Shoenfeld Y, Amital H. Effects of tobacco smoke on immunity, inflammation and autoimmunity. J Autoimmun. 2010;34:J258-65.

13. Tapson VF. The role of smoking in coagulation and thromboembolism in chronic obstructive pulmonary disease. Proceedings of the American Thoracic Society. 2005;2:71-7.

14. Ageno W, Becattini C, Brighton T, Selby R, Kamphuisen PW. Cardiovascular risk factors and venous thromboembolism: a meta-analysis. Circulation. 2008;117:93-102.

15. Cheng YJ, Liu ZH, Yao FJ, Zeng WT, Zheng DD, Dong YG, Wu SH. Current and former smoking and risk for venous thromboembolism: a systematic review and metaanalysis. PLoS Med. 2013;10:e1001515.

16. Nathisuwan S, Dilokthornsakul P, Chaiyakunapruk N, Morarai T, Yodting T, Piriyachananusorn N. Assessing evidence of interaction between smoking and warfarin: a systematic review and meta-analysis. Chest. 2011;139:1130-9.

17. Factors influencing health - Data, indicators: Federal Statistical Office; 2012 [3 August 2015]. Available from:

http://www.bfs.admin.ch/bfs/portal/en/index/themen/14/02/02/key/03.html.html. 
18. Buller HR, Davidson BL, Decousus H, Gallus A, Gent M, Piovella F, Prins MH, Raskob G, van den Berg-Segers AE, Cariou R, Leeuwenkamp O, Lensing AW, Matisse I. Subcutaneous fondaparinux versus intravenous unfractionated heparin in the initial treatment of pulmonary embolism. N Engl J Med. 2003;349:1695-702.

19. Low-molecular-weight heparin in the treatment of patients with venous thromboembolism. The Columbus Investigators. N Engl J Med. 1997;337:657-62.

20. Schulman S, Kearon C, Subcommittee on Control of Anticoagulation of the S, Standardization Committee of the International Society on T, Haemostasis. Definition of major bleeding in clinical investigations of antihemostatic medicinal products in non-surgical patients. Journal of thrombosis and haemostasis : JTH. 2005;3:692-4.

21. Fine JP, Gray RJ. A Proportional Hazards Model for the Subdistribution of a Competing Risk. American Statistical Association. 1999;94:496-509.

22. Landefeld CS, Goldman L. Major bleeding in outpatients treated with warfarin: incidence and prediction by factors known at the start of outpatient therapy. Am J Med. 1989;87:144-52.

23. Beyth RJ, Quinn LM, Landefeld CS. Prospective evaluation of an index for predicting the risk of major bleeding in outpatients treated with warfarin. Am J Med. 1998;105:91-9.

24. Kuijer PM, Hutten BA, Prins MH, Buller HR. Prediction of the risk of bleeding during anticoagulant treatment for venous thromboembolism. Arch Intern Med. 1999;159:457-60.

25. Shireman TI, Mahnken JD, Howard PA, Kresowik TF, Hou Q, Ellerbeck EF. Development of a contemporary bleeding risk model for elderly warfarin recipients. Chest. 2006;130:1390-6.

26. Gmel G, Kuendig H, Notari L, Gmel C, Flury R. Monitorage suisse des addictions Consommation d'alcool, tabac et drogues illégales en Suisse en 2012. Lausanne, Suisse: 2013. 27. Linnemann B, Zgouras D, Schindewolf M, Schwonberg J, Jarosch-Preusche M, Lindhoff-Last E. Impact of sex and traditional cardiovascular risk factors on the risk of recurrent venous thromboembolism: results from the German MAISTHRO Registry. Blood Coagul Fibrinolysis. 2008;19:159-65.

28. Pomp ER, Rosendaal FR, Doggen CJ. Smoking increases the risk of venous thrombosis and acts synergistically with oral contraceptive use. Am J Hematol. 2008;83:97102. 
Philippe Carruzzo, Article SWITCO65+ 


\section{Appendix}

\section{Tables}

Table 1: Baseline characteristics of the patients, by smoking status

\begin{tabular}{|c|c|c|c|c|}
\hline & $\begin{array}{l}\text { Current smokers } \\
\qquad n=76\end{array}$ & $\begin{array}{l}\text { Former smokers } \\
\qquad n=403\end{array}$ & $\begin{array}{l}\text { Never smokers } \\
n=509\end{array}$ & P-value \\
\hline \multicolumn{5}{|l|}{ Socio-demographic } \\
\hline Patient age, median (IQR) & $74.0(69.0 ; 79.0)$ & $74.0(69.0 ; 80.0)$ & $76.0(70.0 ; 82.0)$ & 0.002 \\
\hline Gender (female), n (\%) & 19 (25.0\%) & $123(31 \%)$ & $319(63 \%)$ & $<0.001$ \\
\hline $\begin{array}{l}\text { High school graduate or } \\
\text { more, } \mathrm{n}(\%)\end{array}$ & $36(47 \%)$ & $189(47 \%)$ & $219(43 \%)$ & 0.474 \\
\hline Living status, n (\%) & & & & 0.006 \\
\hline $\begin{array}{l}\text { living at home with } \\
\text { spouse, partner, or } \\
\text { family member }\end{array}$ & $50(66 \%)$ & $281(69 \%)$ & $296(58 \%)$ & \\
\hline living at home alone & $23(30 \%)$ & $113(28 \%)$ & $200(39 \%)$ & \\
\hline living in nursing home & $3(4 \%)$ & $9(2 \%)$ & $12(2 \%)$ & \\
\hline \multicolumn{5}{|l|}{ Smoking characteristics } \\
\hline $\begin{array}{l}\text { Average number of } \\
\text { cigarettes per day, median } \\
\text { (IQR) }\end{array}$ & $15.0(7.0 ; 20.0)$ & $20.0(7.0 ; 25.0)$ & n.a & \\
\hline $\begin{array}{l}\text { Years of smoking, median } \\
\text { (IQR) }\end{array}$ & $48.0(30.0 ; 54.0)$ & $20.5(10.0 ; 38.3)$ & n.a & \\
\hline $\begin{array}{l}\text { Cigarettes in pack-years, } \\
\text { median (IQR) } \\
\text { Comorbidities / History of }\end{array}$ & $30.0(15.0 ; 55.0)$ & $16.0(5.0 ; 40.0)$ & n.a & \\
\hline $\begin{array}{l}\text { Chronic or acute lung } \\
\text { disease, } \mathrm{n}(\%)\end{array}$ & $21(28 \%)$ & $80(20 \%)$ & $53(10 \%)$ & $<0.001$ \\
\hline $\begin{array}{l}\text { Coronary heart disease, } n \\
\text { (\%) }\end{array}$ & $16(21 \%)$ & $91(23 \%)$ & $65(13 \%)$ & $<0.001$ \\
\hline Arterial hypertension, $\mathrm{n}(\%)$ & $48(63 \%)$ & $254(63 \%)$ & $334(66 \%)$ & 0.701 \\
\hline Hypercholesterolemia, n (\%) & $28(37 \%)$ & $129(32 \%)$ & $145(29 \%)$ & 0.241 \\
\hline Diabetes mellitus, n (\%) & $14(18 \%)$ & $74(18 \%)$ & $67(13 \%)$ & 0.080 \\
\hline BMI, median (IQR) & $26.0(23.8 ; 29.8)$ & $26.7(24.1 ; 29.8)$ & $26.8(24.1 ; 30.0)$ & 0.797 \\
\hline Low physical activity, n (\%) & $26(34 \%)$ & $154(38 \%)$ & $187(37 \%)$ & 0.783 \\
\hline \multicolumn{5}{|l|}{ Index VTE characteristics } \\
\hline Type of thrombosis, $n(\%)$ & & & & 0.531 \\
\hline distal DVT only & $6(7.9 \%)$ & $35(8.7 \%)$ & $39(7.7 \%)$ & \\
\hline proximal DVT & $23(30.3 \%)$ & $87(21.6 \%)$ & $113(22.2 \%)$ & \\
\hline pulmonary embolism & $47(61.8 \%)$ & $281(69.7 \%)$ & $357(70.1 \%)$ & \\
\hline Prior VTE, n (\%) & $18(23.7 \%)$ & $128(31.8 \%)$ & $136(26.7 \%)$ & 0.153 \\
\hline Provoked index VTE*, n (\%) & $24(31.6 \%)$ & $128(31.8 \%)$ & $143(28.1 \%)$ & 0.458 \\
\hline $\begin{array}{l}\text { Immobilization during the } \\
\text { last } 3 \text { months, } \mathrm{n}(\%)\end{array}$ & $16(21.1 \%)$ & $98(24.3 \%)$ & $103(20.2 \%)$ & 0.329 \\
\hline $\begin{array}{l}\text { Major surgery during the } \\
\text { last } 3 \text { months, } \mathrm{n}(\%)\end{array}$ & $11(14.5 \%)$ & $65(16.1 \%)$ & $73(14.3 \%)$ & 0.747 \\
\hline $\begin{array}{l}\text { Current oestrogen therapy } \\
\text { during the last } 3 \text { months, } n\end{array}$ & $2(2.6 \%)$ & $12(3.0 \%)$ & $18(3.5 \%)$ & 0.849 \\
\hline
\end{tabular}


Philippe Carruzzo, Article SWITCO65+

\begin{tabular}{|c|c|c|c|c|}
\hline \multicolumn{5}{|l|}{$(\%)$} \\
\hline $\begin{array}{l}\text { Active cancer requiring } \\
\text { therapy, } \mathrm{n}(\%)\end{array}$ & 15 (19.7\%) & $83(20.6 \%)$ & $79(15.5 \%)$ & 0.127 \\
\hline \multicolumn{5}{|l|}{ Bleeding risk factors } \\
\hline Anemia, n (\%) & $25(33 \%)$ & 177 (44\%) & $185(36 \%)$ & 0.093 \\
\hline $\begin{array}{l}\text { History of major bleeding, } n \\
(\%)\end{array}$ & $10(13 \%)$ & $41(10 \%)$ & $50(10 \%)$ & 0.672 \\
\hline $\begin{array}{l}\text { Chronic renal disease or } \\
\mathrm{CrCl}<30, \mathrm{n}(\%)\end{array}$ & $14(18 \%)$ & $92(23 \%)$ & 96 (19\%) & 0.303 \\
\hline $\begin{array}{l}\text { Concomitant antiplatelet } \\
\text { therapy, } \mathrm{n}(\%)\end{array}$ & $29(38 \%)$ & $143(36 \%)$ & $148(29 \%)$ & 0.065 \\
\hline $\begin{array}{l}\text { Type of initial parenteral AC, } \\
\mathrm{n}(\%)\end{array}$ & & & & 0.772 \\
\hline LMWH & $36(47 \%)$ & 193 (48\%) & $234(46 \%)$ & \\
\hline UFH & $26(34 \%)$ & $139(35 \%)$ & 167 (33\%) & \\
\hline Fondaparinux & $13(17 \%)$ & $58(14 \%)$ & 87 (17\%) & \\
\hline Danaparoid & $0(0 \%)$ & $1(0.2 \%)$ & $0(0 \%)$ & \\
\hline None & $1(1 \%)$ & $12(3 \%)$ & $21(4 \%)$ & \\
\hline Vitamin $\mathrm{K}$ antagonist, n (\%) & $61(80 \%)$ & 342 (85\%) & $455(89 \%)$ & 0.028 \\
\hline
\end{tabular}

$N$ number, IQR interquartile range, n.a. non-applicable, VTE venous thromboembolism, DVT deep vein thrombosis, TIA transient ischaemic accident, $\mathrm{CrCl}$ creatinine clearance, $\mathrm{AC}$ anticoagulation Missings $<=0.5 \%$ for every variable except for anemia $(6.4 \%)$.

*Defined as the presence of at least one out of three risk factors: immobilization, major surgery, or current oestrogen therapy during the last three months. 
Table 2 Outcome data

\begin{tabular}{|c|c|c|c|c|}
\hline & $\begin{array}{l}\text { Current smokers } \\
\qquad \mathrm{n}=76\end{array}$ & $\begin{array}{l}\text { Former smokers } \\
\qquad n=403\end{array}$ & $\begin{array}{c}\text { Never smokers } \\
n=509\end{array}$ & P-value \\
\hline $\begin{array}{l}\text { Death during FU, } \mathrm{n}(\%) \\
\text { VTE recurrence }\end{array}$ & $17(22 \%)$ & $89(22 \%)$ & $98(19 \%)$ & 0.536 \\
\hline $\begin{array}{l}\text { VTE recurrence during FU, } \\
\mathrm{n}(\%)\end{array}$ & $8(11 \%)$ & $58(15.1 \%)$ & $54(11 \%)$ & 0.200 \\
\hline $\begin{array}{l}\text { Incidence rate per } 100 \\
\text { patient-years }(95 \%-\mathrm{Cl})\end{array}$ & $5.2(2.6-10.5)$ & $6.6(5.1-8.6)$ & $4.9(3.7-6.4)$ & \\
\hline $\begin{array}{l}\text { Incidence rate ratio }(95 \%- \\
\mathrm{Cl})\end{array}$ & $1.1(0.4-2.8)$ & $1.4(0.9-2.0)$ & 1 (ref.) & \\
\hline $\begin{array}{l}\text { Type of VTE recurrence, } n \\
\text { (\%) }\end{array}$ & & & & 0.729 \\
\hline distal DVT only & 1 (13\%) & $3(5 \%)$ & $5(9 \%)$ & \\
\hline proximal DVT only & $3(38 \%)$ & $16(28 \%)$ & $12(22 \%)$ & \\
\hline $\begin{array}{l}\text { pulmonary } \\
\text { embolism }\end{array}$ & $4(50 \%)$ & $39(67 \%)$ & 37 (69\%) & \\
\hline $\begin{array}{l}\text { Under anticoagulant } \\
\text { therapy at time of VTE } \\
\text { recurrence*, n (\%) }\end{array}$ & $3(38 \%)$ & $17(29 \%)$ & $12(22 \%)$ & 0.540 \\
\hline UFH & $0(. \%)$ & $2(15 \%)$ & $1(11 \%)$ & 0.774 \\
\hline LMWH & $0 \quad(. \%)$ & $1(8 \%)$ & $3(33.3 \%)$ & 0.149 \\
\hline fondaparinux & $0 \quad(. \%)$ & $1(8 \%)$ & $0(0.0 \%)$ & 0.402 \\
\hline VKA & $3(100.0 \%)$ & $14(93 \%)$ & $10(91 \%)$ & 0.858 \\
\hline $\begin{array}{l}\text { Days between index VTE } \\
\text { and recurrence, median } \\
\text { (IQR) } \\
\text { Bleeding }\end{array}$ & $230(105 ; 257)$ & 505 (209; 799) & $396(191 ;$ 678) & 0.320 \\
\hline \multicolumn{5}{|l|}{ Major bleeding } \\
\hline $\begin{array}{l}\text { Major bleeding during FU, } \\
\mathrm{n}(\%)\end{array}$ & $6(8 \%)$ & $59(15 \%)$ & $66(13 \%)$ & 0.271 \\
\hline $\begin{array}{l}\text { Incidence rate per } 100 \\
\text { patient-years }(95 \%-\mathrm{Cl})\end{array}$ & $3.9(1.8-8.8)$ & $6.9(5.3-8.9)$ & $6.0(4.7-7.6)$ & \\
\hline $\begin{array}{l}\text { Incidence rate ratio }(95 \%- \\
\mathrm{Cl})\end{array}$ & $0.7(0.2-1.5)$ & $1.2(0.8-1.7)$ & 1 (ref.) & \\
\hline \multicolumn{5}{|l|}{ Non-major bleeding } \\
\hline $\begin{array}{l}\text { Non-major bleeding } \\
\text { during FU, } \mathrm{n}(\%)\end{array}$ & $17(22 \%)$ & $85(21 \%)$ & $97(19 \%)$ & 0.659 \\
\hline $\begin{array}{l}\text { Incidence rate per } 100 \\
\text { patient-years }(95 \%-\mathrm{Cl})\end{array}$ & $11.4(7.1-18.3)$ & 10.5 (8.5-12.9) & $9.4(7.7-11.4)$ & \\
\hline $\begin{array}{l}\text { Incidence rate ratio }(95 \%- \\
\mathrm{Cl})\end{array}$ & $1.2(0.7-2.0)$ & $1.1(0.8-1.5)$ & 1 (ref.) & \\
\hline
\end{tabular}


Table 3 Association between smoking and risk of VTE recurrence and bleeding events

\begin{tabular}{|c|c|c|c|}
\hline & $\begin{array}{l}\text { Current smokers } \\
\qquad n=76\end{array}$ & $\begin{array}{l}\text { Former smokers } \\
\qquad n=403\end{array}$ & $\begin{array}{c}\text { Never smokers } \\
n=509\end{array}$ \\
\hline \multicolumn{4}{|l|}{ VTE recurrence } \\
\hline Crude SHR $(95 \%-\mathrm{Cl})$ & 1.04 (0.49 to 2.2$)$ & 1.35 (0.93 to 1.96$)$ & 1 (ref.) \\
\hline Adjusted* SHR (95\%-CI) & 1.05 (0.49 to 2.28 ) & 1.33 (0.90 to 1.98$)$ & 1 (ref.) \\
\hline \multicolumn{4}{|l|}{ Bleeding } \\
\hline \multicolumn{4}{|l|}{ Major bleeding } \\
\hline Crude SHR (95\%-Cl) & 0.61 (0.26 to 1.41$)$ & 1.14 (0.80 to 1.61$)$ & 1 (ref.) \\
\hline Adjusted SHR (95\%-CI) & 0.59 (0.25 to 1.39$)$ & 1.09 (0.76 to 1.55$)$ & 1 (ref.) \\
\hline \multicolumn{4}{|l|}{ Non-major bleeding } \\
\hline Crude SHR (95\%-CI) & $1.22(0.73$ to 2.04$)$ & $1.10(0.82$ to 1.47$)$ & 1 (ref.) \\
\hline Adjusted SHR (95\%-CI) & 1.21 (0.73 to 2.02$)$ & 1.09 (0.81 to 1.47$)$ & 1 (ref.) \\
\hline
\end{tabular}

*Adjusted for age, gender, for VTE: prior VTE, provoked VTE, active cancer, overt PE, for bleeding: chronic renal disease or $\mathrm{CrCl}<30 \mathrm{ml} / \mathrm{min}$, history of major bleeding, anemia, and concomitant antiplatelet treatment. 